\title{
Behavior of a manganin coil at elevated temperatures and pressures
}

Jonathan D. Weiss

Daniel L. Decker

dldecker@broadweave.net

H. B. Vanfleet

Follow this and additional works at: https://scholarsarchive.byu.edu/facpub

Part of the Astrophysics and Astronomy Commons, and the Physics Commons

\section{Original Publication Citation}

Weiss, Jonathan D., D. L. Decker, and H. B. Vanfleet."Behavior of a manganin coil at elevated temperatures and pressures." Journal of Applied Physics 47 (1976): 4188-4189.

\section{BYU ScholarsArchive Citation}

Weiss, Jonathan D.; Decker, Daniel L.; and Vanfleet, H. B., "Behavior of a manganin coil at elevated temperatures and pressures" (1976). Faculty Publications. 776.

https://scholarsarchive.byu.edu/facpub/776 accepted for inclusion in Faculty Publications by an authorized administrator of BYU ScholarsArchive. For more information, please contact ellen_amatangelo@byu.edu. 


\title{
Behavior of a manganin coil at elevated temperatures and pressures*
}

\author{
Jonathan D. Weiss, D. L. Decker, and H. B. Vanfleet \\ Department of Physics and Astronomy, Brigham Young University, Provo, Utah 84602 \\ (Received 19 April 1976; in final form 1 June 1976)

\begin{abstract}
We have determined the temperature dependence in the first-order pressure coefficient of a manganin coil to be $d \beta / d T=(4.2 \pm 0.8) \times 10^{-7}\left(\mathrm{kbar}^{\circ} \mathrm{C}\right)^{-1}$ in the equation $R(T, P)=R(T, 0)\left(1+\beta P+\gamma P^{2}\right)$, where $R(T, P)$ is the coil resistance at temperature $T$ and pressure $P$. The measurements were performed by simultaneously measuring the coil resistance and temperature at the transitions of mercury and bismuth, which were observed by differential thermal analysis.
\end{abstract}

PACS numbers: $06.20 . \mathrm{Hq}, 07.35 .+\mathrm{k}, 72.15 . \mathrm{Eb}$

\begin{abstract}
Although manganin resistors have long been used as a secondary pressure standard, they have generally been situated within a pressure system so as to remain at room temperature. However, under circumstances where only limited space is available, such isolation from the high-temperature region is impossible, and a determination of the pressure coefficients of manganin at elevated temperatures is required for its usefulness under those conditions.
\end{abstract}

With the exception of work done by $\mathrm{Wang}^{\mathrm{I}}$ on manganin to $200^{\circ} \mathrm{C}$ and $7 \mathrm{kbar}$, it does not appear as if any experiments along these lines have been performed in a hydrostatic medium. He concluded that, to within the accuracy of his experiments, $k$, the pressure coefficient, is essentially temperature independent to $200^{\circ} \mathrm{C}$. Perhaps a slight increase of $2 \%$ in $k$ over $200^{\circ} \mathrm{C}$ was indicated by his data. Thus, to lowest order, one can write

$$
R(T, P)=R(T, 0)(1+k P),
$$

where $R(T, P)$ is the resistance at a given temperature in ${ }^{\circ} \mathrm{C}$ and pressure. However, at pressures, say, in the 25 -kbar range, other terms must be added to the above expression in order to accurately represent the data. ${ }^{2}$ Considering measurement over a range of temperature and pressure, a simple generalization of $\mathrm{Eq}$. (1) might be

$$
R(T, P)=R(T, 0)\left[1+\left(\beta_{0}+\beta^{\prime} T\right) P+\gamma P^{2}\right],
$$

which includes a linear temperature dependence in the first-order pressure coefficient, and a temperatureindependent, second-order pressure coefficient, $\gamma$. This is equivalent to letting $k$ be a function of $P$ and $T$ such that $k(P, T)=\beta_{0}+\beta^{\prime} T+\gamma P$. Both of these extra terms represent small corrections.

We have performed an experiment to determine a possible temperature dependence of $k$ by placing a 100$\Omega$ manganin coil in a liquid capsule within a multianvil press capable of reaching 25 kbar with the particular pressure cell used. Pressure was determined from the melting curve of mercury ${ }^{3}$ fitted to about $\pm 0.1 \mathrm{kbar}$ below $25 \mathrm{kbar}$ and the bismuth I-II and II-III phase boundaries ${ }^{4}$ known to about $\pm 0.2 \mathrm{kbar}$.

The 2-mil (75 $\Omega / \mathrm{ft})$ manganin wire was wrapped noninductively on a boron nitride form and annealed for two days at $180^{\circ} \mathrm{C}$, the maximum temperature reached in this experiment. Other preparation, such as pressure seasoning or special stress-free winding of the coil, was not attempted, and yet the zero-pressure resistance before and after the measurements differed by less than $0.01 \Omega$ (equivalent to about 45 bar). The form contained a small longitudinal hole into which was placed a Chromel-Alumel thermocouple junction. Due to the small size of the form, the junction was not more than about $2 \mathrm{~mm}$ away from any part of the coil, and so it was assumed that the thermocouple reading was a good representation of the temperature of the entire coil.

A polyethylene cup contained the mercury and bismuth along with another Chromel-Alumel thermocouple with which they were in direct physical contact. The coil and cup were inserted into a thin-walled monel tube (8.8$\mathrm{mm}$ o.d. $\times 0.1-\mathrm{mm}$ wall $\times 36 \mathrm{~mm}$ long) which contained the pressure medium, petroleum ether, and served as a heater. The entire assembly was placed in a hole drilled diagonally through the pyrophyllite cube, $38 \mathrm{~mm}$ on an edge, that was then subjected to pressure from anvils against all six faces. The arrangement is similar to the one described by Decker et al. ${ }^{4}$

The resistance of the coil, as measured by a HewlettPackard 3420B Ratiometer to $0.002 \Omega$, its temperature, and the temperature difference between the mercury or bismuth and the coil were monitored continously on two $X-Y$ recorders as the cell was heated at a given oil pressure. We thus had an automatic reading of the coil resistance and temperature at the onset of the various transitions which were noted by the accompanying thermal arrests.

Since the ratiometer involves a bridge configuration, the measurement of resistance was two-terminal. Thus, certain errors were introduced because of changes in lead resistance resulting from heating and pressurization. Copper leads amounting to about $0.02 \Omega$ inside the pressure vessel introduced a systematic error equivalent to about $0.04 \mathrm{kbar}$ at the highest temperatures reached. This is small compared to other uncertainties in the pressure measurement.

The mercury transition overpressurized at room temperature, so we decided to take as the resistance at the mercury point an extrapolation to room temperature of the resistances measured at elevated temperatures along the melting curve of mercury. A plot of $R(T)$ vs $T\left(P_{\mathrm{Hg} \mathrm{I}-\mathrm{L}}\right)$ was fitted very well to a straight line, and $R\left(25^{\circ} \mathrm{C}\right)$ was determined from the least- 
squares parameters led to a value of $k$ of $2.46 \times 10^{-3}$ $\mathrm{kbar}^{-1}$. Such a value is completely consistent with previous measurements. ${ }^{5}$

A similar procedure was required for the bismuth I-II point, but in this case, because of the size of the pyrophyllite cube, the system was not quite able to reach the onset of that transition. Since $d T / d P<0$ for that phase boundary, it was reached by heating. This time $R(T)$ vs $T\left(P_{\mathrm{BI} \text { I-II }}\right)$ was fitted very closely to a quadratic function. The pressure of this transition at $25^{\circ} \mathrm{C}$ was assigned values of $25.7 \pm 0.1 \mathrm{kbar}$. While the equilibrium pressure is known to be $25.5 \mathrm{kbar},{ }^{5}$ the initiation pressure depends rather sensitively on the size of the sample, speed of pumping, etc. ${ }^{6}$ The exhaustive study by Zeto and Vanfleet ${ }^{6}$ of the bismuth transformation indicates that the overpressurization of the bismuth in our case was probably no more than 0.2 kbar above the equilibration pressure. The manganin coil resistance at atmospheric pressure and room temperature, $R_{0}$, along with the values at the bismuth and mercury points gave $\beta(25)=(2.48 \pm 0.04) \times 10^{-3} \mathrm{kbar}^{-1}$ and $\gamma=(12 \pm 23) \times 10^{-7} \mathrm{kbar}^{-2}$. In retrospect, the large uncertainty in $\gamma$ was due as much to the lack of reproducibility of $R_{0}$ as to uncertainties in the transition pressures.

The over-all difficulty in determining $\gamma$ accurately should be appreciated, however. The experimental uncertainty in that coefficient as reported by Zeto and Vanfleet ${ }^{2}$ is about $9 \times 10^{-7} \mathrm{kbar}^{-2}$ in spite of the pains they took to properly season their coil, measure its resistance accurately, and know the bismuth transition pressure with great precision.

In order to examine the temperature dependence of $\beta$, the quantity $[R(T, P)-R(T, 0)] / R(T, 0) P=k(P, T)$ was computed for all the observed transitions. $R(T, 0)$ was taken from an atmospheric-pressure measurement of the coil resistance made to $180^{\circ} \mathrm{C}$. The data were then fitted to a function of the form $\beta_{0}+\beta^{\prime} T+\gamma P$, consistent with the assumption made in Eq. (2). The results were $\beta_{0}=(2.48 \pm 0.02) \times 10^{-3} \mathrm{kbar}^{-1}, \beta^{\prime}=(4.2 \pm 0.8) \times 10^{-7}$ $\left(\operatorname{kbar}^{\circ} \mathrm{C}\right)^{-1}$, and $\gamma=(5 \pm 14) \times 10^{-7} \mathrm{kbar}^{-2}$, and predict about a $3 \%$ change in $k$ in going from 25 to $200^{\circ} \mathrm{C}$. This prediction is in basic agreement with Wang's conclusion, but does not give the same result as that reported by Samara and Giardini. ${ }^{7}$ However, their experiment was performed in a solid pressure medium and thus involved nonhydrostatic stresses on their coil.

In order to demonstrate the reasonableness of fit, the quantity $k$ was plotted against pressure (see Fig. 1)

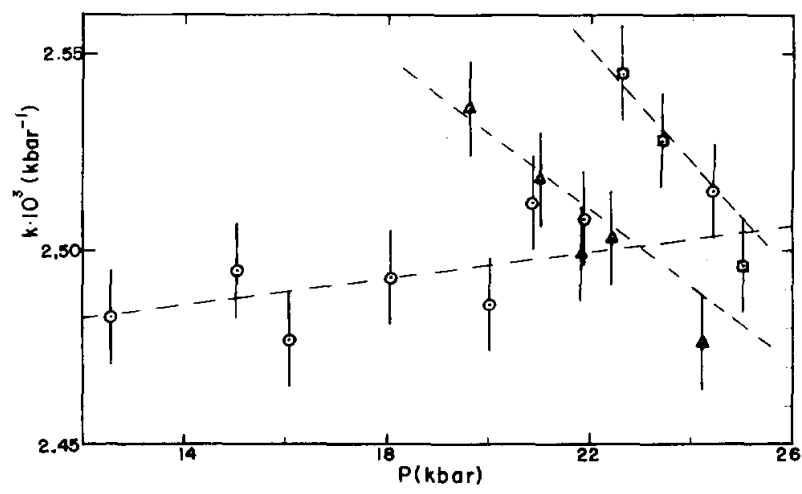

FIG. 1. Pressure coefficient of manganin coil vs pressure along the mercury melting curve, $\odot$, the bismuth (I-II), $\Delta$, and bismuth (II-III), $\nabla$, phase boundaries.

along the mercury melting curve and the bismuth I-II and bismuth II-III phase boundaries. Under these circumstances, the temperature and pressure are, of course, not independent of each other. Now $d T / d P$ $=\beta^{\prime} d T / d P+\gamma$ along all three phase boundaries, where $d T / d P \approx 5.1,-21$, and $-33^{\circ} \mathrm{C} / \mathrm{kbar}$ for the mercury and two bismuth phase lines, respectively, at $0^{\circ} \mathrm{C}$. The lines drawn on the graph were based on our calculated values of $k$ along these phase boundaries. The difference in slopes among them is a direct consequence of the existence of a nonzero value of $\beta^{\prime}$. Furthermore, the correspondence between the data and the fit, while not perfect, does demonstrate that our deduced value of $\beta^{\prime}$ is indeed reasonable.

*Research supported by National Science Foundation.

${ }^{1} \mathrm{C}$. Wang, Rev. Sci. Instrum. 38, 24 (1967).

${ }^{2}$ R.J. Zeto, and H.B. Vanfleet, J. Appl. Phys. 40, 2227 (1969).

${ }^{3}$ V. S. Bogdanov, Yu. L. Levin, S. S. Sekoyan, and Yu. I. Shmin, in Accurate Characterization of the High-Pressure Environment, edited by E.C. Lloyd (NBS, Washington, D. C., 1971).

${ }^{4}$ D. L. Decker, J. D. Jorgensen, and R.W. Young, High Temp. -High Pressures 7, 331 (1975).

${ }^{5}$ D. L. Decker, W. A. Bassett, L. Merrill, H. T. Hall, and J. D. Barnett, J. Phys. Chem. Ref. Data 1, 773 (1972). ${ }^{6}$ R. J. Zeto and H. B. Vanfleet, J. Appl. Phys. 42, 1001 (1971).

${ }^{7}$ G. A. Samara and A. A. Giardini, Rev. Sci. Instrum. 35, 489 (1964). 